\title{
Effects of Different Cogging Technologies on the Inclusions in GH4738 Superalloy Produced by Double Vacuum Smelting
}

\author{
Zhengyang Chen ${ }^{1,2}$, Shufeng Yang ${ }^{1,2 *}$, Jingshe $\mathrm{Li}^{1,2}$, Hao Guo ${ }^{1,2}$, Hongbo Zheng ${ }^{1,2}$ \\ 1 School of Metallurgical and Ecological Engineering, University of Science and Technology Beijing, Beijing \\ 100083, China; chenzhengyang@xs.ustb.edu.cn(Z.C.); lijingshe@ustb.edu.cn(J.L.); \\ guohaoustb@sina.com(H.G.); hongbozhengp@hotmail.com(H.Z.) \\ 2 Beijing Key Laboratory of Special Melting and Preparation of High-End Metal Materials, Beijing 100083, \\ China \\ * Correspondence: yangshufeng@ustb.edu.cn; Tel.: +86-185-1169-5668
}

\begin{abstract}
Cogging is a key part in the production process of superalloy, but inclusions affect the performance of superalloy. It is therefore particularly important to study the effects of cogging on the inclusions in superalloy. In our study, the superalloy GH4738 was made by double vacuum smelting. Cogging was performed by unidirectional drawing, upsetting and drawing, and upsetting/drawing with radial forging. The types and distributions of the inclusions after the three cogging processes were analyzed using scanning electron microscopy, energy dispersive spectroscopy, and software such as Image Pro Plus. The results showed that double vacuum smelting essentially determined the types of the inclusions in the GH4738 superalloy. Four types of inclusions were found in the experiments: TiC-TiN-Mo-S composite, TiC-TiN composite, Ce-Mo-S composite, and $\mathrm{SiC}$ inclusions. In the case of cogging by unidirectional drawing, the average size of the inclusions first decreased and then increased, from the center to the edge. In the case of upsetting and drawing, and upsetting/drawing with radial forging, the average size of inclusions decreased from the center to the edge.
\end{abstract}

Keywords: superalloy; double vacuum smelting; cogging; inclusion.

\section{Introduction}

As aerospace engines are moving toward better reliability, higher thrust-to-weight ratio, and larger size, the requirements on the temperature and mechanical performances of the key engine components such as turbine disks and blades [1-5] are becoming more stringent. Superalloys, with properties of excellent high-temperature strength, good resistance to oxidation, hot corrosion resistance temperature, etc. [6-8], have become indispensable materials for manufacturing aerospace engine components, and have garnered the reputation of providing "a new generation of superalloys for every generation of aircraft" [9-11].

Inclusions affect the performance of superalloys and their growth is typically controlled in two ways by researchers. Some modify the smelting process to reduce the content of undesirable elements or improve the purity of alloys, enhancing their performance. For example, Degawa et al. [12] prepared IN738 and MarM247 alloys by vacuum induction melting in a CaO crucible and found less than $10 \mathrm{ppm}$ of $\mathrm{N}, \mathrm{O}$, and $\mathrm{S}$ (each) in the ingots, with significantly improved ingot quality. Schneider et al. [13] found that higher ingot purity was obtained by using a low-frequency alternating current for the electroslag remelting, instead of direct current. Shevchenko et al. [14] demonstrated that the time variation and asymmetric distribution of the arc in vacuum-arc remelting did not facilitate slag discharge by the molten pool, affecting the purity of the ingots. Appropriate arc control can effectively improve the ingot quality. 
Other scientists attempted to improve the alloy properties by studying and manipulating the type, size, morphology, distribution, and evolution of the inclusions [15-17]. Wang et al. [18] analyzed the inclusions at different positions in a $20 \mathrm{Cr} 13$ hot-rolled stainless-steel round bar and gained insight into the changes in the inclusions from the edge to the center, thus helping the growth control and elimination of inclusions in hot-rolled bars. Kawakami et al. [19] studied the generation mechanisms of nonmetallic inclusions in high-cleanliness steel and discovered that the reduction of inclusion size during secondary refining was effective in enhancing the alloy properties. Jiang et al. [20] researched the evolution mechanisms of nonmetallic inclusions in high-strength alloyed steel and identified that the steel-slag reaction time had a major influence on the type, composition, and shape of the inclusions. These results led to the conclusion that appropriate control over the type and morphology of the inclusions could improve the fatigue resistance of the alloys.

Summing up, most scientists tried to reduce the amount of inclusions in superalloys by adjusting the smelting process, i.e., by improving the purity and thus, the performance of the alloys. However, there have been very few reports on the types and distributions of the inclusions created during the superalloy processing by other means. In view of this, we performed double vacuum smelting of the superalloy GH4738, followed by cogging via unidirectional drawing, upsetting and drawing, and upsetting/drawing with radial forging. The type, percentage, size change, and distribution of the inclusions in the superalloy GH4738 were observed and recorded to analyze the effects of the three cogging modes on the inclusion type and distribution. This work lays a theoretical foundation for improving the performance of the superalloys.

\section{Experimental Procedure}

In this experiment, three GH4738 ingots with a diameter of $508 \mathrm{~mm}$ were fabricated by vacuum induction melting and vacuum arc remelting (double vacuum smelting). Their chemical composition is shown in Table 1. Each ingot was then subjected to a different cogging technique: unidirectional drawing, upsetting and drawing, and upsetting/drawing with radial forging, to yield bars of uniform size. The $15 \mathrm{~mm} \times 15 \mathrm{~mm} \times 15 \mathrm{~mm}$ samples used in the experiments were cut from the center, from a point at a distance of $1 / 2 R$ ( $R$ is the radius) from the center, and from the edges of the transverse and longitudinal sections of the bars. The sampling positions are as shown in Figure 1.

The metal samples were polished mechanically. The size, morphology, and composition of the inclusions were characterized by a scanning electron microscope-energy dispersive spectrometer (SEM-EDS). To obtain inclusion data with better accuracy, each sample was divided into four zones, and 25 different viewing fields were selected in each zone to carry out the statistical analysis. The Image Pro Plus software was used to analyze the average size and distribution of the inclusions.

Table 1. Chemical composition of GH4738 superalloy (\%)

\begin{tabular}{llllllll}
\hline $\mathbf{C r}$ & $\mathbf{C}$ & Co & Mo & Al & Ti & S & Ni \\
\hline 18.92 & 0.07 & 13.13 & 3.96 & 1.47 & 2.97 & $<0.15$ & Balance \\
\hline
\end{tabular}

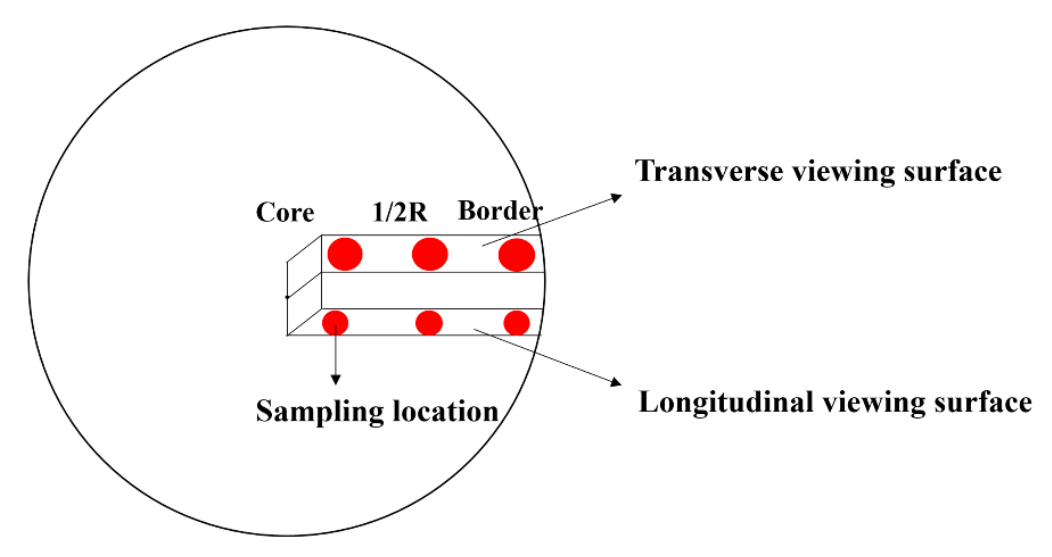


Figure 1. Schematic diagram of sample position.

\section{Results and Discussions}

Figure 2 shows the morphology of some inclusions along various directions and at different locations in the superalloy GH4738 samples, made by the three cogging modes. As shown in the figure, the morphologies and sizes of the inclusions are essentially the same, making it difficult to obtain an accurate description of the effects of the individual cogging methods on the inclusions. Therefore, it is necessary to analyze statistically each image of the inclusion morphology, to find out the types and distributions of the inclusions in the superalloy.
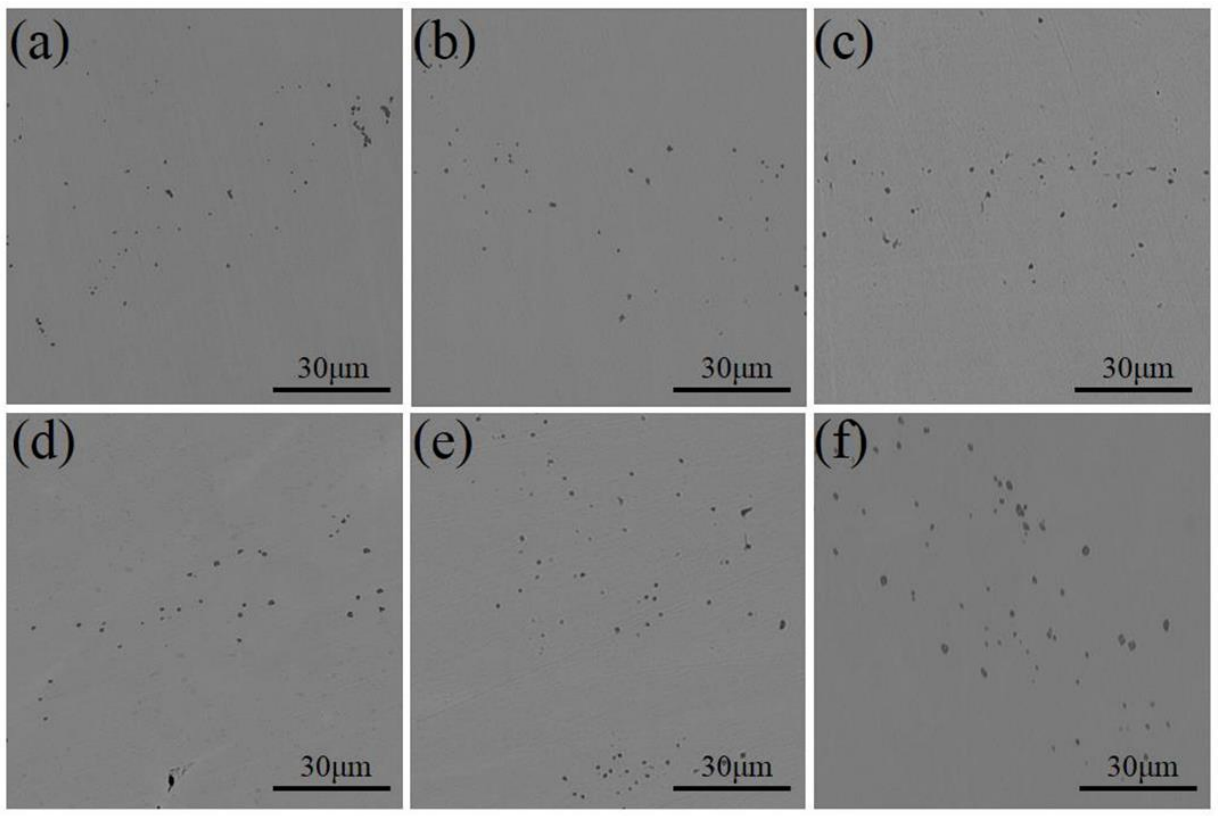

Figure 2. Morphology of inclusions in superalloy GH4738: (a), (b), and (c) show the transverse sections of the samples obtained through unidirectional drawing, upsetting and drawing, and upsetting/drawing with radial forging. (d), (e), and (f) show the longitudinal transverse sections of the samples obtained through unidirectional drawing, upsetting and drawing, and upsetting/drawing with radial forging.

\subsection{Inclusion Type and Percentage Contribution}

The data collection and analysis of the types and percentages of the inclusions in the samples from different cogging methods indicate nearly identical results, which show the minute influence of the different cogging techniques on the inclusion type and percentage. For this reason, the double vacuum smelting process should be considered in the data analysis. Owing to the length restrictions of this paper, only the inclusion types and percentages in the samples from one cogging method are analyzed in detail here, and are shown in Figures 3, 4, 5, and 6.

Five different types of inclusions can be identified in the samples in these figures, of which four are dominant: TiC-TiN-Mo-S composite, TiC-TiN composite, Ce-Mo-S composite, and SiC inclusions. Among them, the TiC-TiN-Mo-S composite inclusions take up the highest proportion of $75 \%$ and exist in two different forms as illustrated in Figure 3 (a) and (b). The composite inclusions could have been formed during superalloy smelting as different types of inclusions collided, combined, or were enriched at the surface because of the circulation and convection of the molten metals and the different densities of the various inclusions [21]. 


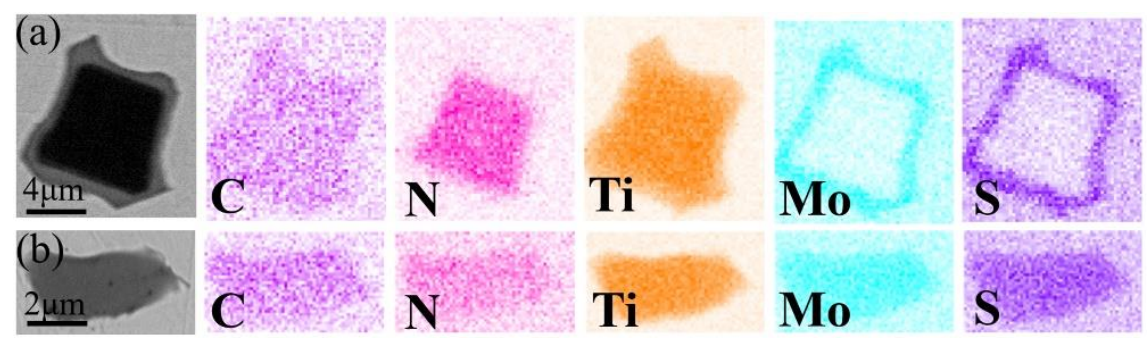

Figure 3. SEM images of the two types of TiC-TiN-Mo-S inclusions.

From Figure 4 (a) and (b), it can be seen that composite inclusions are formed by both $\mathrm{TiC}$ and TiN. As TiN has lower standard Gibbs free energy of formation than $\mathrm{TiC}$, it preferentially nucleates. $\mathrm{TiC}$ then precipitates on the surface of $\mathrm{TiN}$, aggregates and grows, forming TiC-TiN composite inclusions. Both the compounds are of the face-centered cubic structure with similar lattice constants, and easily form solid solutions during their growth. Therefore, no clear nucleation center is observed [22].

An analysis of Figure 4 (c) and (d) reveals no Ce among the constituents of the superalloy GH4738; however, Ce-Mo-S inclusions are found in the ingots. This is caused by the inadequate purity level of some revert or raw material fed during the vacuum induction melting of the superalloy GH4738 smelting, which leads to Ce contamination and formation of Ce-Mo-S inclusions.

In Figure 4 (e) and (f), it is observed that, in the smelting of the superalloy GH4738 by vacuum induction melting, $\mathrm{C}$ is added into the furnace as a deoxidizing agent to form $\mathrm{CO}$, removing oxygen in the process. As the oxygen concentration drops gradually in the liquid metal, less $\mathrm{CO}$ is produced. A part of this cannot be released because of the small bubble size, and remains attached to the crucible wall. This facilitates a reaction between a fraction of the $\mathrm{CO}$ with the $\mathrm{Si}$ in the crucible wall material, producing $\mathrm{SiC}$ inclusions [23].
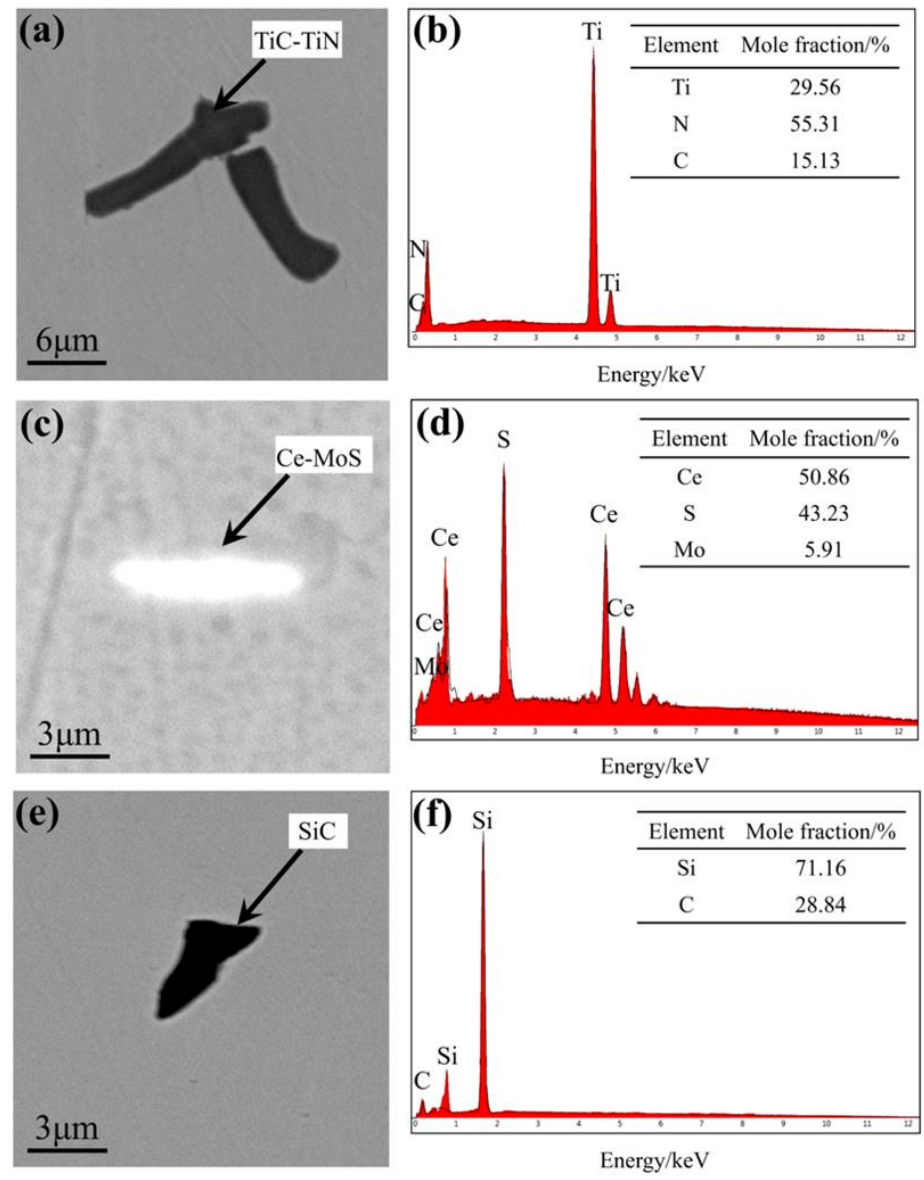
Figure 4. SEM images and EDS mapping of TiC-TiN, Ce-Mo-S, and SiC inclusions: (a) and (b): TiC$\mathrm{TiN}$; (c) and (d): Ce-Mo-S; (e) and (f): $\mathrm{SiC}$

The remaining inclusion types make up the least proportion of $2 \%$, among the five types. Although the number of undesirable elements could be kept at a low level in the double vacuum smelting of superalloy GH4738, some trace elements were still segregated to form inclusions, as shown in Figure 5 (a), (b), and (c).

From the above analyses, it can be inferred that the three cogging methods have minute influences on the inclusion types and their percentages in the superalloy GH4738. Instead, the material purity in double vacuum smelting, refining time of vacuum induction melting, slag discharge extent of metal molten pool in vacuum arc remelting, etc., are the determining factors.
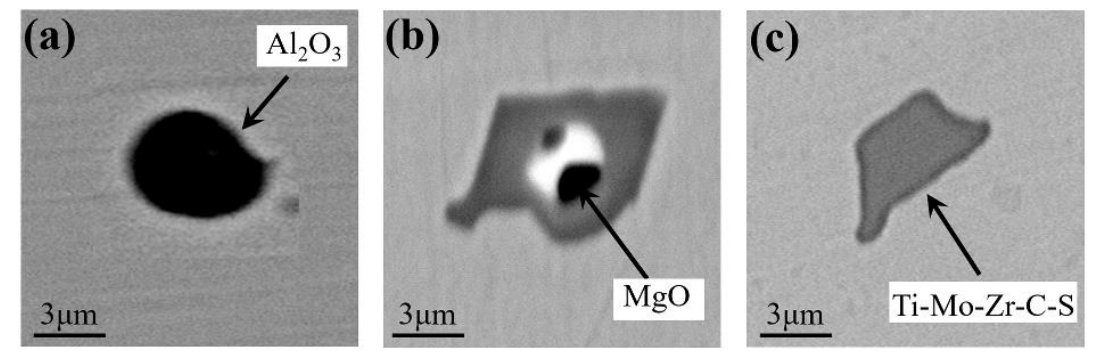

Figure 5. SEM images of other inclusions: (a) $\mathrm{Al}_{2} \mathrm{O}_{3} ;$ (b) $\mathrm{MgO}$; (c) Ti-Mo-Zr-C-S

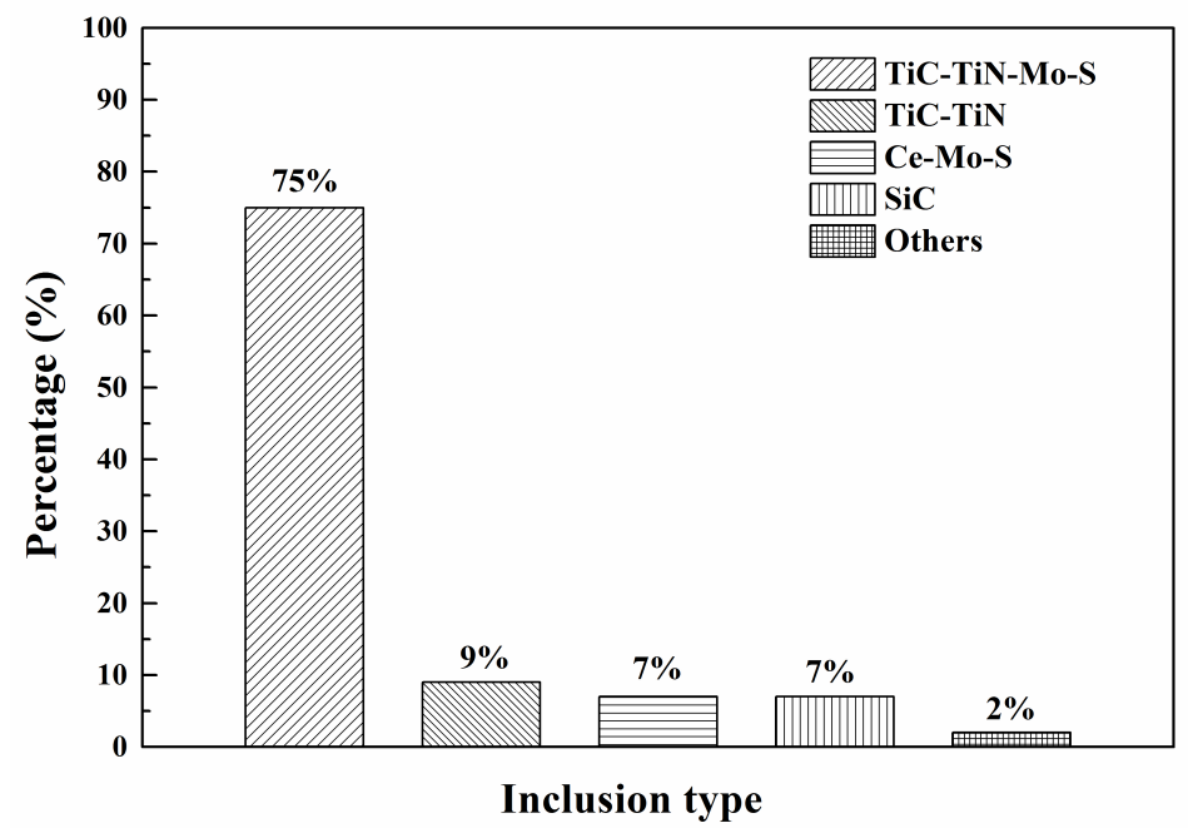

Figure 6. Proportions of various types of inclusions in superalloy GH4738

\subsection{Distribution of Inclusions in the Transverse and Longitudinal Directions}

Figures 7 and 8 give the distributions of the inclusions along the transverse and longitudinal directions for the three cogging modes. Analyzing both figures, it can be seen that, for cogging by unidirectional drawing (the first group), the average size of the inclusions first decreases and then increases, from the center to the edge. At $1 / 2 R$, inclusions with sizes less than $2 \mu \mathrm{m}$ constitute the highest percent, resulting in the lowest average size of inclusions at that spot. According to the classical plasticity theory [24], deformation rarely happens in the contact region between the forged piece and the plate; thus, inclusions in this region do not undergo much deformational fracture when force is applied. The average size of inclusions at the edge is larger compared to that at $1 / 2 R$. As pointed out in reference [25], for cogging by unidirectional drawing, the average chord length of the 
grains at the center is greater than that at $1 / 2 R$, which indicates that a larger deformation force is experienced by the inclusions at $1 / 2 R$, compared to that at the center; i.e., large inclusions undergo deformational fracture or are broken into numerous small inclusions more readily. The average inclusion size is therefore smaller at $1 / 2 R$ than at the center. In conclusion, cogging by unidirectional drawing primarily affects the sizes of the inclusions at the $1 / 2 R$ position in the alloys.

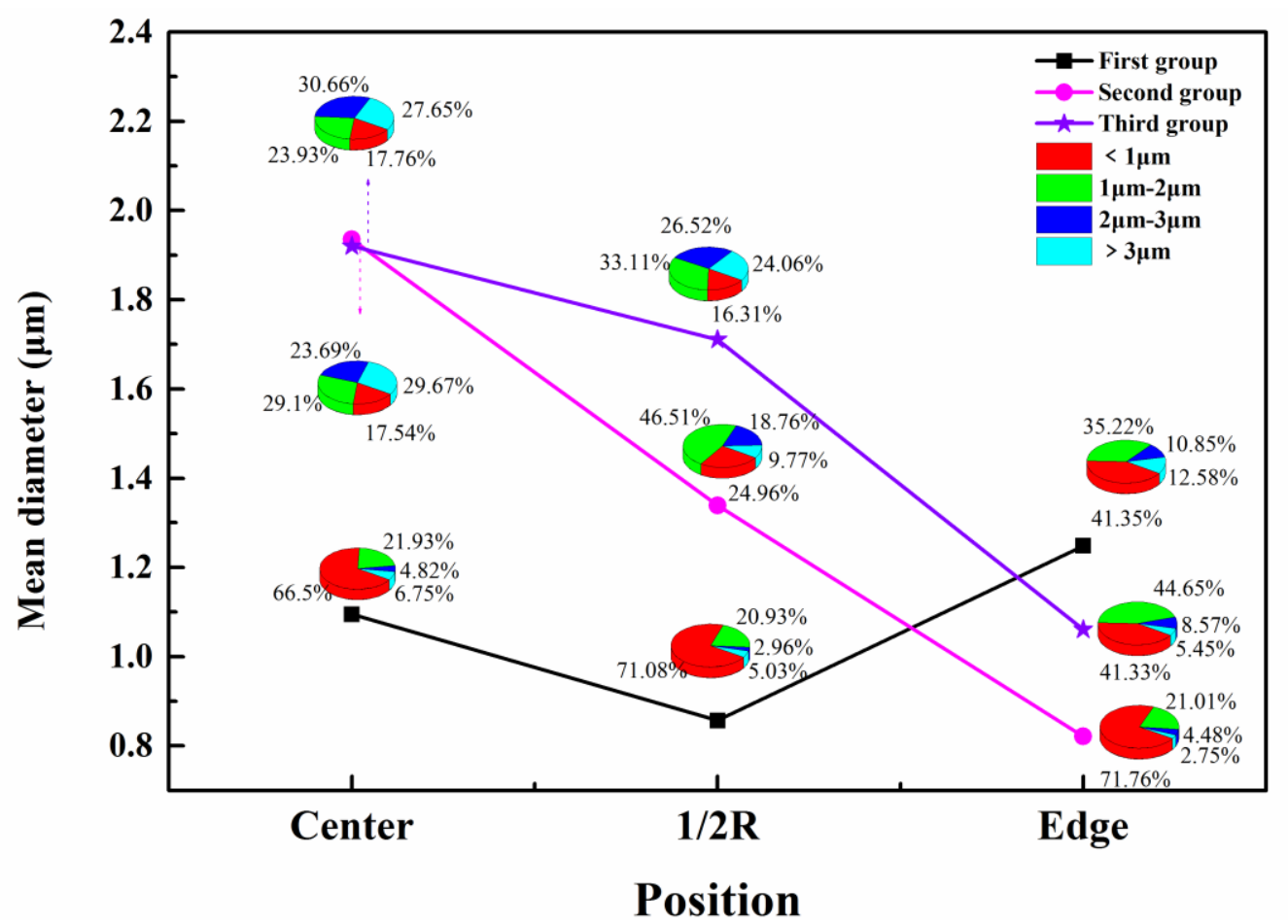

Figure 7. Inclusion distributions in the transverse direction for the three cogging modes

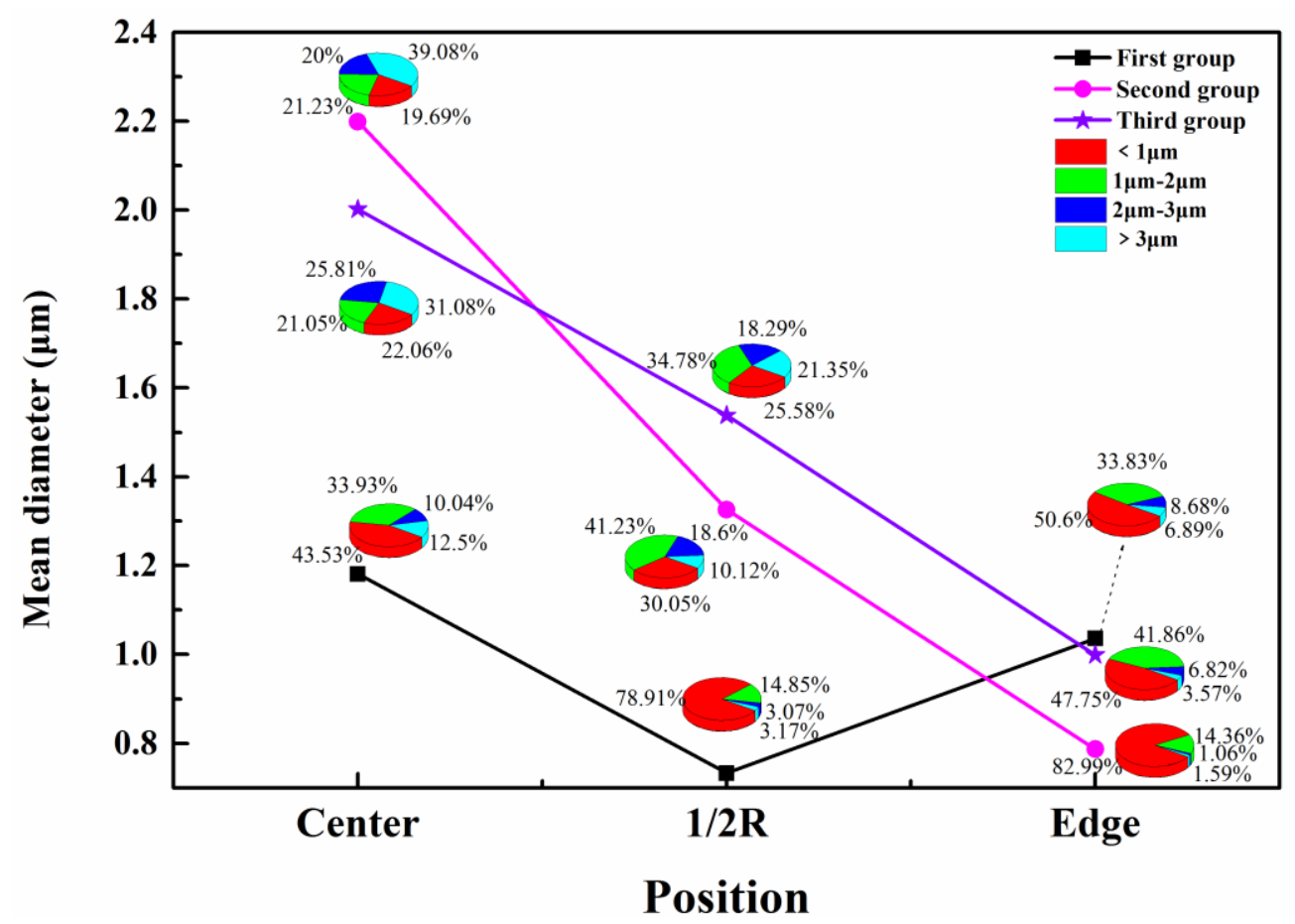

Figure 8. Inclusion distributions in the longitudinal direction for the three cogging modes 
With upsetting and drawing used in cogging (the second group), the sharp increase in the percentage of inclusions with sizes less than $2 \mu \mathrm{m}$, from the center, to $1 / 2 \mathrm{R}$, and to the edge shows the rapid decrease in the average inclusion size in that direction. This is due to the large deformation energy generated in the forged piece during repeated upsetting and drawing, making the temperature of the whole work piece difficult to drop. As the alloy structure at the center cools slower, it has lower forging penetration efficiency and degree of deformation [26]. The internal inclusions there undergo less deformational fracture or breaking and, as such, are the largest in average size. However, multidirectional deformation caused by repeated upsetting and drawing also intensifies the degree of fracture and breaking among the inclusions at $1 / 2 R$ and along the edge, making some of them more dispersed in distribution [27]. Furthermore, cooling happens much faster at the edge than at $1 / 2 R$, facilitating the dispersion of fine inclusions. The average size of inclusions is therefore the smallest at the edge. From the above, we can conclude that cogging by upsetting and drawing mainly affects the inclusion size at the alloy edge.

When the ingots go through upsetting/drawing with radial forging during cogging (the third group), the percentages of the inclusions of different sizes at the center, at $1 / 2 R$, and along the edge show a significant increase for inclusions of size less than $2 \mu \mathrm{m}$, forming a trend of decreasing average inclusion size from the center to the edge. As shown in reference [28], the grain size is the finest at the edge for a work piece subjected to radial forging. This means that the effect of radial forging is mainly seen in the grain size at the edge, and the grain refinement at the edge is accompanied by a reduction in the inclusion size there. Considering the variations in the average inclusion size from the center to the $1 / 2 R$ point and to the edge of a forged piece subjected to upsetting and drawing, as described in the previous section, it appears that the third cogging method chiefly affects the inclusion size at the alloy edge.

\section{Conclusions}

This study presents an analysis of the effects of three different cogging techniques: unidirectional drawing, upsetting and drawing, and upsetting/drawing with radial forging, on the inclusions in the GH4738 superalloy. The superalloy was fabricated by double vacuum smelting and cogging was performed. The type, percentage, size change, and distribution of the inclusions in the superalloy GH4738 were observed and recorded to analyze the effects of the three cogging modes on the inclusion type and distribution. The following conclusions were drawn from this study:

1. The three cogging methods have minimal impact on the inclusion type and percentage of the superalloy GH4738. The double vacuum smelting process, on the other hand, plays a determining role. Four types of inclusions were found in this experiment, in the superalloy: TiCTiN-Mo-S composite, TiC-TiN composite, Ce-Mo-S composite, and SiC inclusions.

2. For GH4738 cogging by unidirectional drawing, the average size of the inclusions first decreased and then increased from the center to the edge. This technique primarily affected the inclusion size at the $1 / 2 R$ point of the superalloy.

3. For cogging of GH4738 by upsetting and drawing, and upsetting/drawing with radial forging, the average size of the inclusions decreased from the center to the edge. These two techniques primarily affected the inclusion size at the edge of the superalloy.

Acknowledgments: This research is supported by the National Science Foundation of China (Nos. 51734003).

Author Contributions: Zhengyang Chen conceived and designed the experiments and interpreted the data; Zhengyang Chen and Shufeng Yang wrote the paper; Jingshe Li analyzed the data and collected the literatures; Hao Guo and Hongbo Zheng performed the experiments.

Conflicts of Interest: The authors declare no conflict of interest. 


\section{References}

1. Williams, J.C.; Jr, E.A.S. Progress in structural materials for aerospace systems. Acta Mater. 2003, 51, 5775-5799.

2. Decker, R.F. The evolution of wrought age-hardenable superalloys. JOM. 2006, 58, 32-36.

3. Zhang, B.J.; Zhao, G.P.; Zhang, W.Y.; Huang. S.; Chen, S.F. Investigation of high performance disc alloy GH4065 and associated advanced processing techniques. Acta Metall. Sin. 2015, 51, 1227-1234.

4. Shi, Ch.X.; Zhong, Z.Y. Development and innovation of superalloy in China. Acta Metall. Sin. 2010, 46, 1281-1288.

5. Hegde, S.R.; Kearsey, R.M.; Beddoes, J.C. Designing homogenization-solution heat treatments for single crystal supperalloys. Mat. Sci. Eng. A. 2010, 527, 5528-5538.

6. Furuya, Y.; Matsuoka, S.; Kimura, T.; Hayaishi, M. Effects of inclusion and ODA sizes on gigacycle fatigue properties of high-strength steels. Tetsu to Hagane. 2005, 91, 630-638.

7. Li, M.H.; Sun, X.F.; Jin, T.; Guan, H.R.; Hu, Z.Q. Oxidation behavior of a single-crystal Ni-base superalloy in air-II: at 1000, 1100 and $1150^{\circ}$ C. Oxid. Met. 2003, 60, 195-210.

8. Kirka, M.M.; Brindley, K.A.; Neu, R.W.; Antolovich, S.D.; Shinde, S.R.; Gravett, P.W. Influence of coarsened and rafted microstructures on the thermomechanical fatigue of a Ni-base superalloy. Int. J. Fatigue. 2015, 81, 191-201.

9. Mao, J.; Chang, K.M.; Yang, W.H.; Ray, K.; Vaze, S.P.; Ferrer, D.U. Cooling precipitation and strengthening study in powder metallurgy superalloy U720LI. Metall. Mater. Trans. A. 2001, 32, 24412452.

10. Carter, J.L.W.; Kuper, M.W.; Uchic, M.D.; Mills, M.J. Characterization of localized deformation near grain boundaries of superalloy René-104 at elevated temperature. Mat. Sci. Eng. A. 2014, 605, 127-136.

11. Radis, R.; Schaffer, M.; Albu, M.; Kothleitner, G.; Pölt, P.; Kozeschnik, E. Multimodal size distributions of $\gamma^{\prime}$ precipitates during continuous cooling of UDIMET 720 Li. Acta Mater. 2009, 57, 5739-5747.

12. Degawa, T.; Ototani T. Refining of high purity Ni-base superalloy using calcia refractory. Tetsu to Hagane. 1987, 73, 1691-1697.

13. Schneider, R.S.E.; Mülleder, M.; Zeller, P.; Würzinger, P.; Reiter, G.; Paul, S. Effects of low frequency alternating currents on the electro-slag remelting process. BHM. 2016, 161, 20-26.

14. Shevchenko, D.M.; Ward, R.M. Liquid metal pool behavior during the vacuum arc remelting of INCONEL 718. Metall. Mater. Trans. B. 2009, 40, 263-270.

15. Wang, X.H.; Jiang, M.; Chen, B.; Li, H.B. Study on formation of non-metallic inclusions with lower melting temperatures in extra low oxygen special steels. Sci. China Technol. Sc. 2012, 55, 1863-1872.

16. Ma, J.; Zhang, B.; Xu, D.K.; Han, E.H.; Ke, W. Effects of inclusion and loading direction on the fatigue behavior of hot rolled low carbon steel. Int. J. Fatigue. 2010, 32, 1116-1125.

17. Furuya, Y.; Hirukawa, H.; Kimura, T.; Hayaishi, M. Gigacycle fatigue properties of high-strength steels according to inclusion and ODA sizes. Metall. Mater. Trans. A. 2007, 38, 1722-1730.

18. Wang, X.C.; Wang, H.N.; Cheng, G.G.; Kou, Y.S.; Zuo, H.; Chen, L. Characteristics of inclusions in 20Cr13 stainless steel hot-rolled round bar. Chin. Metall. 2014, 24, 17-21.

19. Kawakami, K.; Taniguchi, T.; Nakashima, K. Generation mechanisms of non-metallic inclusions in high-cleanliness steel. Tetsu To Hagane. 2008, 93, 743-752.

20. Jiang, M.; Wang, X.H.; Chen, B.; Wang W.J. Laboratory study on evolution mechanisms of non-metallic inclusions in high srength alloyed steel refined by high basicity slag. ISIJ Int. 2010,50, 95-104.

21. Tang, Z.J.; Guo, T.M.; Kou, Z.S.; Fu, Y.; Jin, S. Feature and formation mechanism of inclusions in K4169 Ni-based superalloy. Chin. J. Nonferrous Metal. 2015, 25, 2403-2413.

22. Toro, A.; Zhou, F.; Wu, M.H.; Geertruyden, W.V.; Misiolek, W.Z. Characterization of non-metallic inclusions in superelastic NiTi tubes. J. Mater. Eng. Perform. 2009, 18, 448-458.

23. Shen, J.; Xia, T.D.; Wang, X.J.; Feng, X.C. Characterization and analysis of non-metallic inclusions in Ni42-Fe expansive alloy. T. Nonferr. Metal. Soc. 2007, 17, s1165-s1171.

24. Wang, W.; Ma, R.; Zhao, J.; Zhai, R.X. Co-simulation technology of casting-forging combination forming process for grain distribution prediction. Mater. Rev. 2017, 31, 150-154.

25. Chen, W.; Liu, J.S.; Dang, S.E. Uniformity control of deformation and microstructure in stretching process of large axial forging. J. Plastic. Eng. 2015, 5, 13-17. 
26. Zhang, Z.; Li, J.Y.; Peng F.; Xi, J.H.; Mu, G.L.; Ge, P. Effect of upsetting and drawing mode on structure homogeneity of TC4 titanium alloy bars. Spec. Steel Technol. 2017, 1, 54-56.

27. Du, J.H.; Zhao, G.P.; Deng, Q.; Lv, X.D.; Zhang, B.J. Development of wrought superalloy in China. J. Aeronaut. Mater. 2016, 3, 27-39.

28. Kong, Y.H.; Li, L.; Zhu, S.G.; Chen, G.S. Study on microstructures and properties of different part in radial forged Gh4169 alloy. Rare Metal. Met. Eng. 2010, 39, 405-408. 